\title{
Article \\ Enhanced Performance of Cyclopentadithiophene-Based Donor-Acceptor-Type Semiconducting Copolymer Transistors Obtained by a Wire Bar-Coating Method
}

\author{
Doyeon Kim ${ }^{1,+}$, Minho Yoon ${ }^{1,+}$ and Jiyoul Lee ${ }^{1,2, *(\mathbb{D})}$ \\ 1 Department of Smart Green Technology Engineering, Pukyong National University, Busan 48513, Korea; \\ dy6425@naver.com (D.K.); minhoyoon78@gmail.com (M.Y.) \\ 2 Department of Nanotechnology Engineering, Pukyong National University, Busan 48513, Korea \\ * Correspondence: jiyoul_lee@pknu.ac.kr \\ + These authors contributed equally to this work.
}

check for updates

Citation: Kim, D.; Yoon, M.; Lee, J.

Enhanced Performance of

Cyclopentadithiophene-Based

Donor-Acceptor-Type

Semiconducting Copolymer

Transistors Obtained by a Wire

Bar-Coating Method. Polymers 2022,

14, 2. https://doi.org/10.3390/

polym14010002

Academic Editor: Bożena Jarząbek

Received: 30 November 2021

Accepted: 17 December 2021

Published: 21 December 2021

Publisher's Note: MDPI stays neutral with regard to jurisdictional claims in published maps and institutional affiliations.

Copyright: (C) 2021 by the authors. Licensee MDPI, Basel, Switzerland. This article is an open access article distributed under the terms and conditions of the Creative Commons Attribution (CC BY) license (https:// creativecommons.org/licenses/by/ $4.0 /)$.

\begin{abstract}
Herein, we report the fabrications of high-performance polymer field-effect transistors (PFETs) with wire bar-coated semiconducting polymer film as an active layer. For an active semiconducting material of the PFETs, we employed cyclopentadithiophene-alt-benzothiadiazole (CDT-BTZ) that is a D-A-type-conjugated copolymer consisting of a repeated electron-donating unit and an electron-accepting unit, and the other two CDT-based D-A-type copolymer analogues are cyclopentadithiophene-alt-fluorinated-benzothiadiazole (CDT-FBTZ) and cyclopentadithiophenealt-thiadiazolopyridine (CDT-PTZ). The linear field-effect mobility values obtained from the transfer curve of the PFETs fabricated with the spin-coating were $0.04 \mathrm{~cm}^{2} / \mathrm{Vs}, 0.16 \mathrm{~cm}^{2} / \mathrm{Vs}$, and $0.31 \mathrm{~cm}^{2} / \mathrm{Vs}$, for CDT-BTZ, CDT-FBTZ, and CDT-PTZ, respectively, while the mobility values measured from the PFETs with the wire bar-coated CDT-BTZ film, CDT-FBTZ film, and CDT-PTZ film were $0.16 \mathrm{~cm}^{2} / \mathrm{Vs}, 0.28 \mathrm{~cm}^{2} / \mathrm{Vs}$, and $0.95 \mathrm{~cm}^{2} / \mathrm{Vs}$, respectively, which are about 2 to 4 times higher values than those of the PFETs with spin-coated films. These results revealed that the aligned molecular chain is beneficial for the D-A-type semiconducting copolymer even though the charge transport in the D-A-type semiconducting copolymer is known to be less critical to the degree of disorder in film.
\end{abstract}

Keywords: cyclopentadithiophene-based conjugated polymer; polymer field-effect transistors; wire-bar coating; charge transport; Gaussian density of states (DOS)

\section{Introduction}

In recent decades, solution-processable polymer field-effect transistors (PFETs) based on conjugated copolymers with donor-acceptor (D-A)-type moieties, such as indacenodithiophene (IDT) [1,2], diketopyrrolopyrrole (DPP) [3,4], isoindigo (IDG) [5,6], naphthalenediimide (NDI) [7-9], and cyclopentadithiophene (CDT) [10-12], have received extensive attention due to their remarkably high field-effect mobilities exceeding $10 \mathrm{~cm}^{2} \mathrm{~V}^{-1} \mathrm{~s}^{-1}$ and low-energy bandgap characteristics. Rigid and nearly torsion-free planar polymer backbones in the D-A-conjugated copolymers have been regarded to be attributed to the enhanced charge transport along the chain and efficient interchain charge transfer through the strong $\pi-\pi$ interaction between adjacent D-A subunits [13-15]. Several approaches, such as designing the D-A building blocks for controlling the push-pull strength of donor and acceptor moieties [16,17] and modification of the side chains [18], have been suggested for improving the molecular-structure of D-A-conjugated copolymers and electrical properties. However, polymers inherently have the twisted or tangled structures, of which disordered phases inevitably exist in the films [19-22]. Since the disordered phase impedes the charge transport due to the trap sites, it is necessary to minimize the twisting or tangle of the polymer molecular chains present in the polymer thin film channel of the PFETs and to align them well to obtain the PFETs with higher performance. 
In this study, we report that the structural and electrical characteristics of the barcoated polymeric films with cyclopentadithiophene-alt-benzothiadiazole (CDT-BTZ) and the other two CDT-based D-A-type copolymers of cyclopentadithiophene-alt-fluorinatedbenzothiadiazole (CDT-FBTZ) and cyclopentadithiophene-alt-pyridine thiadiazole (CDT-PTZ). Bar coating is a widely used, large-area coating method for polymer films [23]. Through this bar coating, which allows the polymeric films to be gradually dried from the edge to center, aligned macroscopic structures and nano-fibril microstructures with large grains have been successfully formed [20]. Moreover, the bar-coated PFETs show the enhanced p-type charge-transport characteristics: The hole currents have been significantly increased with the threshold shifts and field-effect mobilities have been improved by factors of $2 \sim 4$. The temperature-variable current-voltage analyses of the bar-coated PFETs reveals that the molecular ordering leads to the trap states of the polymeric films to be significantly minimized, and results in the high-performance PFETs. Therefore, it is strongly believed that the well-ordered polymer structures with enhanced electrical characteristics of the CDT-based films can be achieved by the bar-coating method.

\section{Experimental Methods}

Top-gate, bottom-contact PFETs were fabricated, as shown in Figure 1a. A chemically cleaned soda-lime glass (Corning EAGLE Glass) was used as a substrate, and $\mathrm{Ti}(5 \mathrm{~nm}) / \mathrm{Au}(35 \mathrm{~nm})$ was thermally evaporated onto the substrate and patterned using conventional lift-off methods for source/drain electrodes. The channel width and length of PFETs were 1000 and $20 \mu \mathrm{m}$, respectively. The conjugated semiconducting copolymers (i.e., CDT-BTz (Mw $(\sim 60,000)$ with a polydispersity index (PDI) of 2.5), CDT-FBTz (Mw $(\sim 75,000)$ with a PDI of 2.5$)$, and CDT-PTz (Mw $(\sim 60,000)$ with a PDI of 2.5$))$ were purchased from ONE-Materials Inc. (Dorval, QC, Canada) and used as received. The chemical structures of the CDT-based D-A-type copolymers are shown in Figure 1c. To fabricate the thin-film coatings, the semiconducting polymer solutions dissolved in chloroform at a concentration of $10 \mathrm{mg} / \mathrm{mL}$ were deposited using bar coating, as shown in Figure 1c, and subsequently thermally annealed at $200^{\circ} \mathrm{C}$ for $60 \mathrm{~min}$ in nitrogen ambient, resulting in a $60-\mathrm{nm}$-thick semiconducting polymer film. Next, for the top-gate dielectric, PMMA (dissolved in n-butyl acetate at a concentration of $80 \mathrm{mg} / \mathrm{mL}$ ) was spin-coated and cured at $80^{\circ} \mathrm{C}$ for $60 \mathrm{~min}$. The thickness of the PMMA was measured to be $240 \mathrm{~nm}$, and its geometric capacitance was $6.86 \mathrm{nF} \mathrm{cm}{ }^{-2}$ at $1 \mathrm{kHz}$. Finally, the top-gate electrode was formed by thermally evaporating an 80 -nm-thick layer of $\mathrm{Al}$ through a shadow mask. The film thicknesses were confirmed using Field Emission Scanning Electron Microscope (FE-SEM) (MIRA 3, TESCAN).

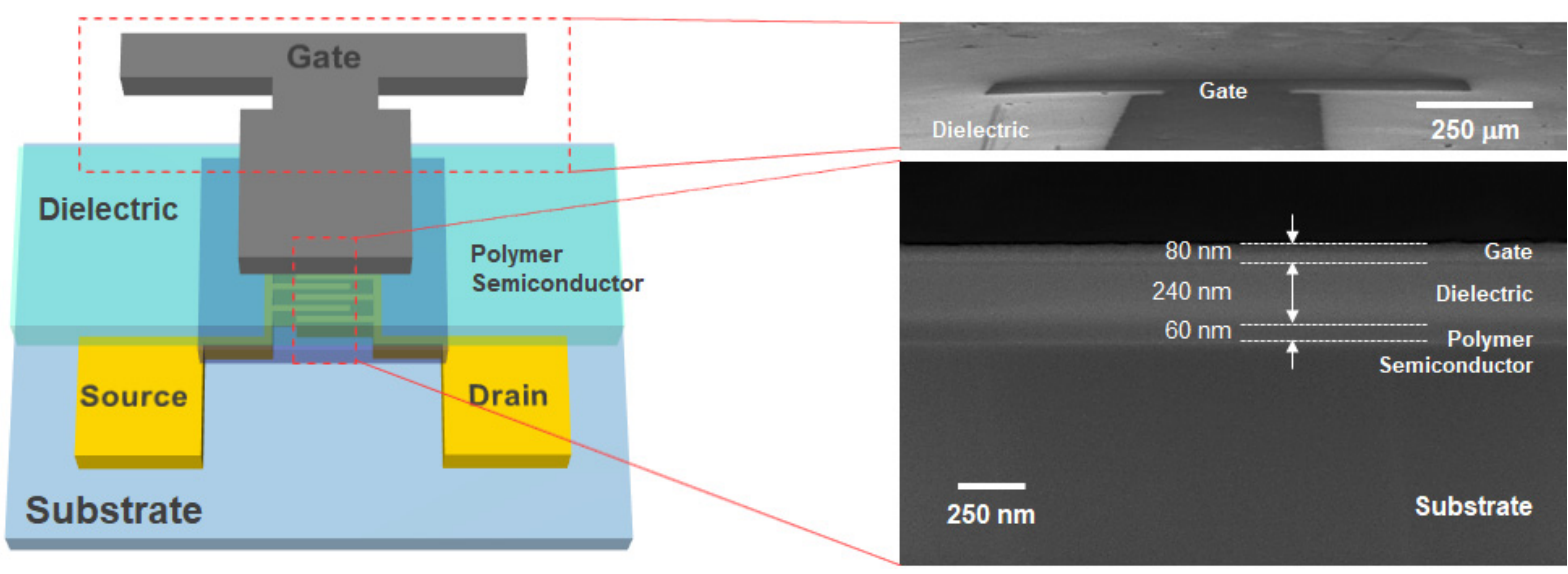

(a)

Figure 1. Cont. 


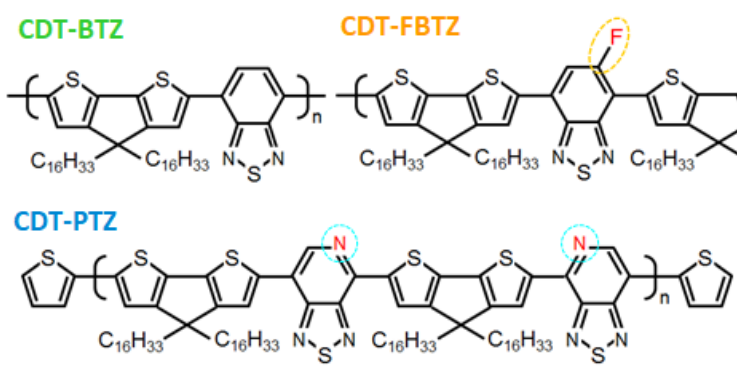

(b)

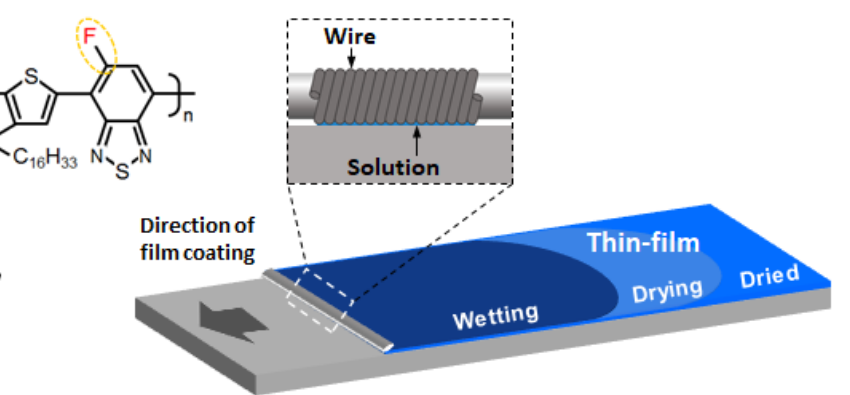

(c)

Figure 1. (a) Device configuration of the PFET used in this study and corresponding SEM images. (b) Molecular structures of the D-A-type semiconducting copolymers. (c) Schematic illustration of the wire-bar-coating process.

The current-voltage $(I-V)$ characteristics of the PFETs were characterized using a Keithley 236 Source Measure Unit in combination with a Keithley 2635 Source Meter controlled using a LabVIEW code. Capacitance-voltage $(C-V)$ measurements of the polymer dielectric layers were recorded using an LCR meter (HP4284A, Agilent Technologies, Santa Clara, CA, USA). A liquid nitrogen cooling cryostat was used for the temperaturedependent (160-300 K) I-V measurements. The field-effect mobility of the FETs in the linear regime was found using the following equation:

$$
\mu_{\text {lin }}=\frac{1}{C_{i} V_{d s}} \frac{L}{W} \frac{\partial I_{d s}}{\partial V_{g s}}
$$

where $I_{d s}$ is the drain current, $V_{g s}$ is the gate voltage, $C_{i}$ is the geometric dielectric capacitance, $V_{d s}$ is the drain voltage, and $L$ and $W$ are the channel length and width, respectively. All the electrical signals of the PFETs were measured in the dark.

\section{Results and Discussion}

Figure 2a-f displays the cross-polarized optical microscope images of spin- and barfilms in Figure $2 \mathrm{~d}-\mathrm{f}$, the aligned polymeric structure, in accordance with the coating direction, can be observed. Spin coating is a widely used, solution-processable, thinfilm deposition method using centrifugal force, of which the thickness of the film can be determined by the spinning speed and viscosity of the solution. However, the instantaneous solvent evaporation during the process leads to the polymeric films to be hardly aligned. In contrast, as schematically illustrated in Figure $1 b$, the bar coating uses the wound-wire bar along a fixed substrate, which enables the wet film to be gradually dried from the edge to the center $[20,21]$. Thus, the polymeric films could be confined and uniaxially aligned, as observed. In addition, when the microscopic surface morphologies of the films were investigated with atomic force microscopy (AFM), in Figure 3, nano-fibril microstructures with large grains were definitely found in the bar-coated films. Although the directional structures, as in Figure 2, were hardly found, probably due to the polymeric molecular structure of the long chain and high molecular weight, it was clearly evident that the barcoating method offers the larger, grainy, micro-film structures, which obviously attributed to the gradual drying from the edge to the center. The mean grain sizes for the bar-coated CDT-PTZ, CDT-FBTZ, and CDT-BTZ films were estimated to be 3.6, 9.5, and $9.2 \mathrm{~nm}$, whereas those of the spin-coated films were 2.2, 7.4, and $8.1 \mathrm{~nm}$, respectively. In addition, the root mean square (rms) surface roughness of the bar-coated films clearly increased and were measured to be 1.2, 0.8, and $1.1 \mathrm{~nm}$ for the bar-coated CDT-PTZ, CDT-FBTZ, and CDT-BTZ films, whereas it was $0.9,0.6$, and $0.8 \mathrm{~nm}$ for the spin-coated films, respectively. 


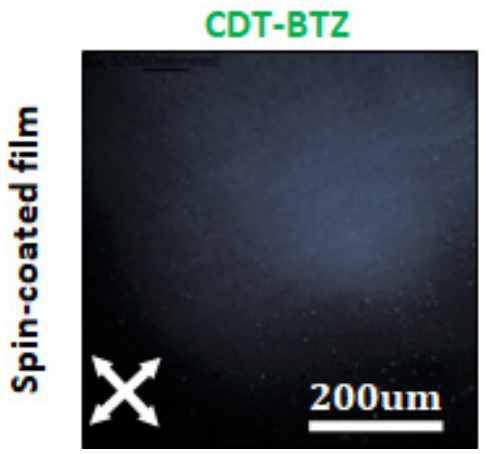

(a)

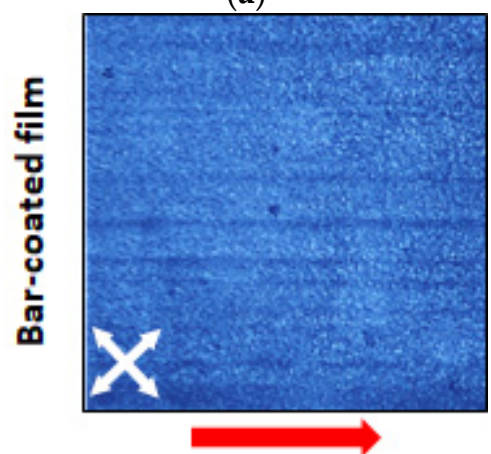

(d)

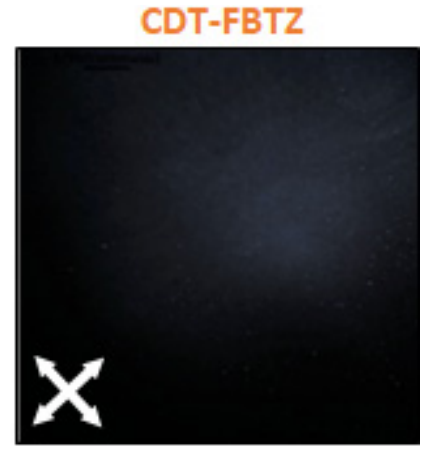

(b)

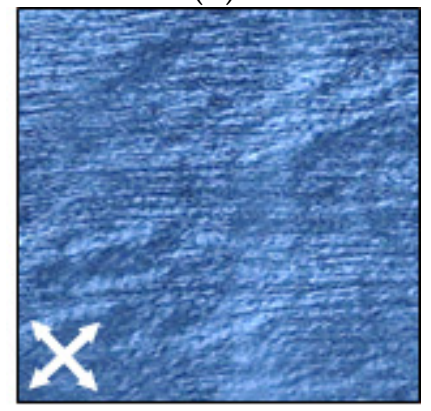

(e)

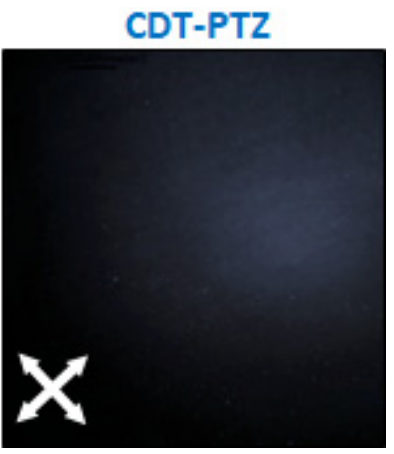

(c)

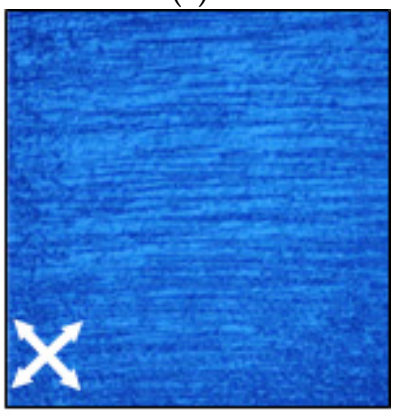

(f)

Figure 2. Cross-polarized optical microscope images of spin- and bar-coated films. (a,d) CDT-BTZ, $(\mathbf{b}, \mathbf{e})$ CDT-FBTZ, and (c,f) CDT-PTZ films. Red arrow is wire-bar coating direction.

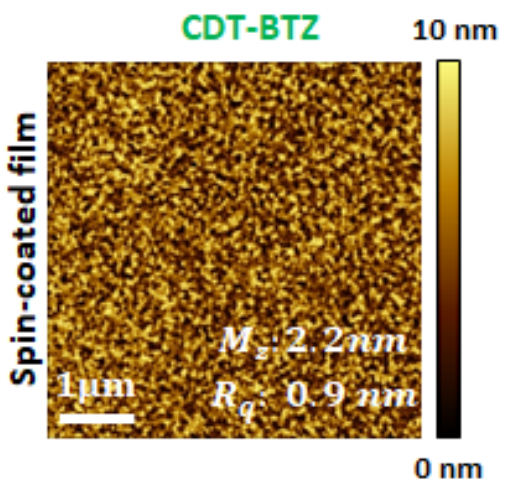

(a)

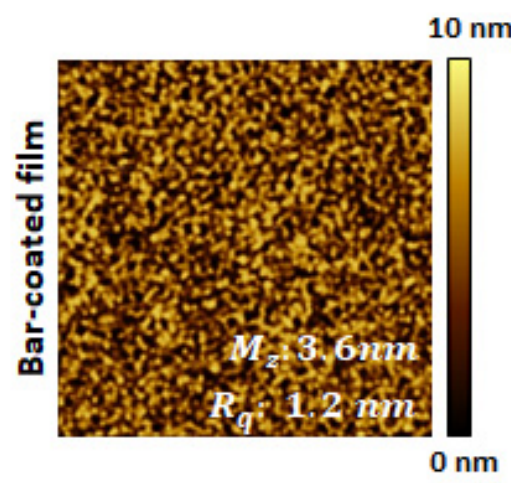

(d)

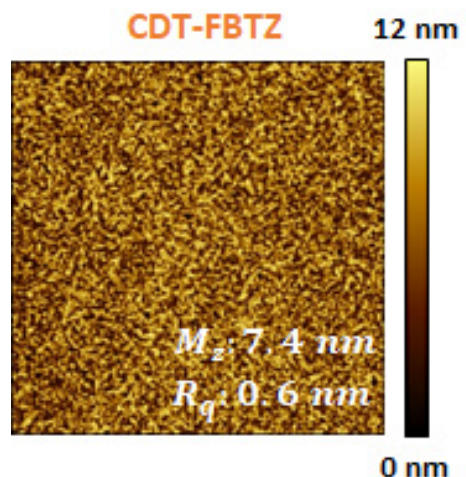

(b)

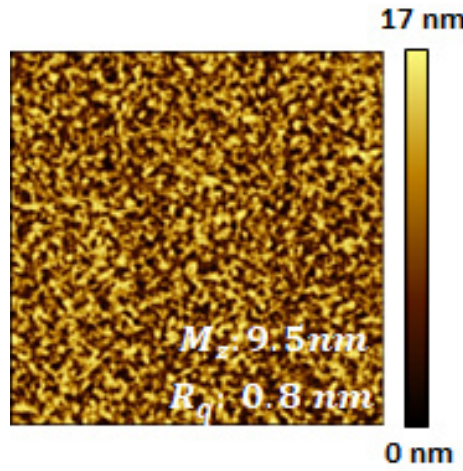

(e)

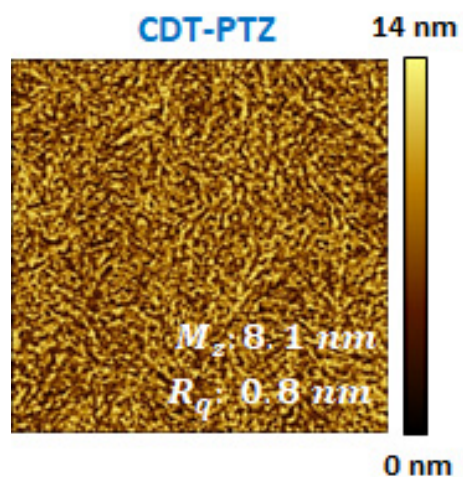

(c)

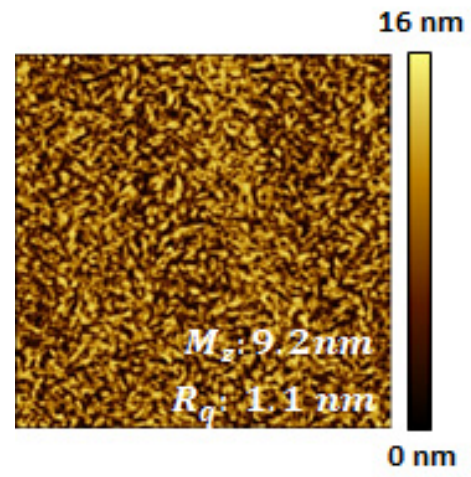

(f)

Figure 3. AFM images of spin- and bar-coated films of (a,d) CDT-BTZ, (b,e) CDT-FBTZ, and (c,f) CDT-PTZ films. 
Moreover, UV/Vis absorption spectra of the films clearly showed the bar-coatingdriven structural ordering in the CDT-based polymer films. As shown in Figure 4, all the D-A polymer films exhibited a high energy peak between 400 to $500 \mathrm{~nm}$, corresponding to the $\pi-\pi^{*}$ transition, and a low energy peak between 700 to $1000 \mathrm{~nm}$, which was attributed to the intramolecular charge transition [24-26]. More noteworthy, aggregation peaks, which were located at 830, 835, and $1000 \mathrm{~nm}$, were identified for the bar-coated CDT-BTZ, CDTFBTZ, and CDT-PTZ films. Furthermore, the intramolecular peaks were clearly red-shifted by 12,6 , and $6 \mathrm{~nm}$ for the films. As reported in [27], the emergence of those additional peaks and the red shifts was regarded to be attributed to the molecular aggregation. By stacking with the same adjacent polymer sub-units, the relevant energy states of the conjugated polymers (additional peaks) were formed, thereby resulting in decreases in the optical band gap of the polymeric films.

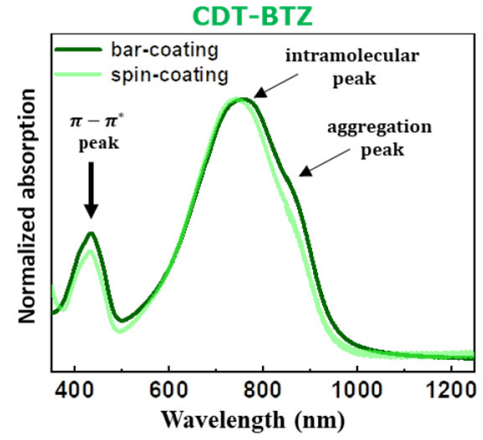

(a)

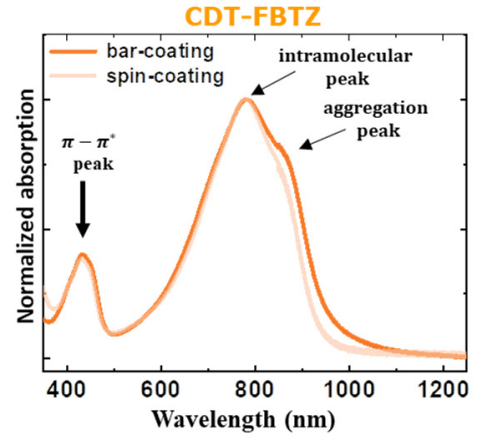

(b)

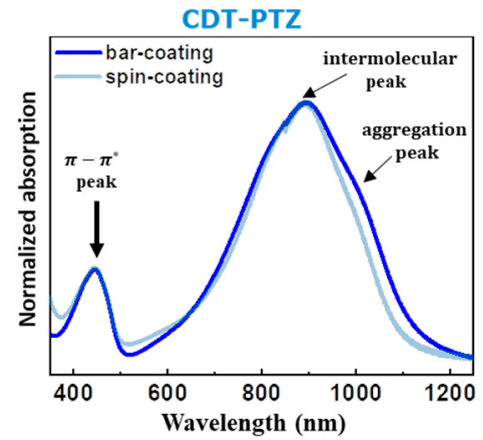

(c)

Figure 4. UV-vis absorbance spectra for spin- and bar-coated films of (a) CDT-BTZ, (b) CDT-FBTZ, and (c) CDT-PTZ films.

Next, top-gate, bottom-contact PFETs were fabricated and their current-voltage characteristics were investigated by measuring 20 samples at each condition (see Figure S1 of the Supplementary Materials). Figures $5 \mathrm{a}-\mathrm{c}$ and $5 \mathrm{~d}-\mathrm{f}$, respectively, display the transfer characteristics $\left(I_{d s}\right.$ vs. $\left.V_{g s}\right)$ of PFETs with spin-coated and bar-coated CDT-BTZ, CDT, FBTZ, and CDT-PTZ films and the corresponding output characteristics $\left(I_{d s}\right.$ vs. $\left.V_{d s}\right)$ of the PFETs. In all the cases of the CDT-based-PFETs, hole conduction of the bar-coated PFETs was remarkably enhanced. Compared to that of the spin-coated PFETs, the hole currents $\left(I_{d s}\right.$ at $\left.V_{g s}=-60 \mathrm{~V}\right)$ of the bar-coated PFETs increased by an order of magnitude, and the threshold voltages $\left(V_{t h}\right)$ of the PFETs were shifted to the depletion mode, which indicates the enhanced p-type conduction. The maximum transconductance of the barcoated CDT-BTZ, CDT-FBTZ, and CDT-PTZ PFETs was estimated to be 3.1, 4.9, and $17 \mu \mathrm{s}$, respectively, whereas those of the spin-coated PFETs were deduced to be $0.6,3.0$, and $6.2 \mu \mathrm{s}$. Meanwhile, the linear field-effect hole mobility of the spin-coated CDT-BTZ, CDT-FBTZ, and CDT-PTZ PFETs was estimated to be $0.04,0.16$, and $0.31 \mathrm{~cm}^{2} \mathrm{~V}^{-1} \mathrm{~s}^{-1}$, but significantly increased by factors of 2 4, and was $0.16,0.28$, and $0.95 \mathrm{~cm}^{2} \mathrm{~V}^{-1} \mathrm{~s}^{-1}$ for the bar-coated PFETs, respectively. Note that the gate leakage currents of the PFETs were maintained below $\sim 10^{-9} \mathrm{~A}$ in the bias range. The device parameters are summarized in Table 1 . In addition, the aging effect on the device performances of the spin- and bar-coated PFETs was investigated. As shown in Figure S2 of the Supplementary Materials, the PFETs were quite stable up to 30 days: On-current levels $\left(V_{g s}=-60 \mathrm{~V}\right)$ were almost unchanged and only off-levels $\left(V_{g s}=\sim 0 \mathrm{~V}\right)$ were slightly decreased in an order. We considered that these stable operations of the PFETs were attributed to the top gate device geometry, of which the polymeric films were passivated with the top gate dielectric, and also to the subsequent annealing step at a relatively high temperature of $200^{\circ} \mathrm{C}$ for $60 \mathrm{~min}$ in nitrogen ambience for the films. 
CDT-BTZ

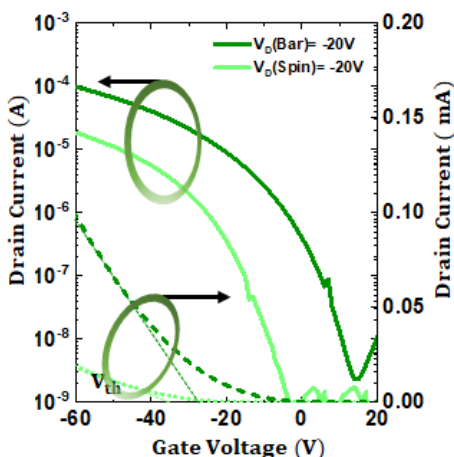

(a)

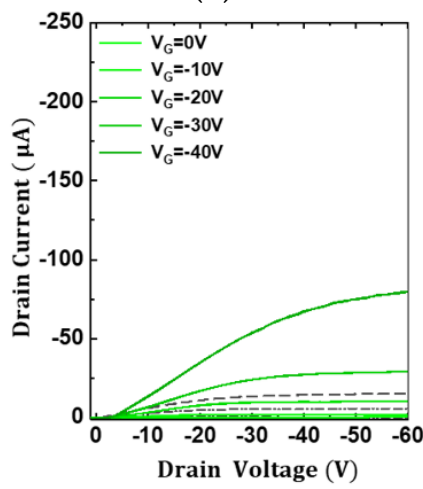

(d)

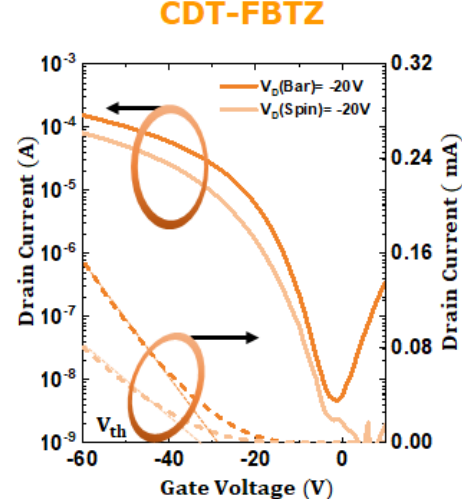

(b)

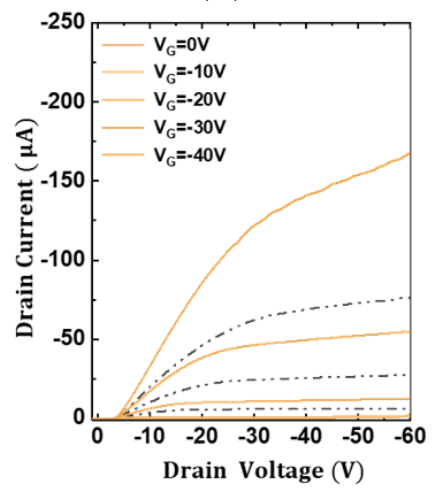

(e)

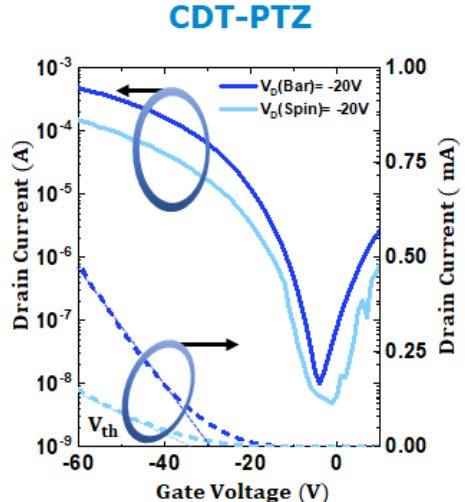

(c)

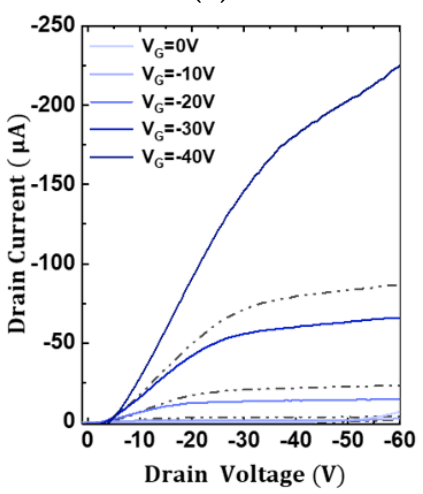

(f)

Figure 5. Linear regime transfer characteristics of the bar-coated and spin-coated (a) CDT-BTZ-, (b) CDT-FBTZ-, and (c) CDT-PTZ-based PFETs in the linear regime $\left(V_{D S}=-20 \mathrm{~V}\right)$. The output curves of the (d) CDT-BTZ-, (e) CDT-FBTZ-, and (f) CDT-PTZ-based PFETs with the bar-coating and spin-coating.

Table 1. Summary of device parameters and Gaussian DOS parameters for bar-coated and spin-coated CDT series-based PFETs.

\begin{tabular}{|c|c|c|c|c|c|c|c|}
\hline \multirow{2}{*}{\multicolumn{2}{|c|}{ Coating Method }} & \multicolumn{3}{|c|}{ Device Parameter } & \multicolumn{3}{|c|}{ DOS Parameter } \\
\hline & & $g_{m}\left(\times 10^{-6} \mathrm{~S}\right)$ & $m_{\text {lin }}\left(\mathrm{cm}^{2} \mathrm{~V}^{-1} \mathrm{~s}^{-1}\right)$ & $V_{t h}(\mathrm{~V})$ & $E_{A}(\mathrm{meV})$ & $N\left(\mathrm{~cm}^{-2}\right)$ & $\sigma(\mathrm{meV})$ \\
\hline \multirow{2}{*}{ CDT-BTZ } & Bar-coating & 3.1 & 0.16 & -25 & 89 & $4.2 \times 10^{13}$ & 95 \\
\hline & Spin-coating & 0.6 & 0.04 & -33 & 116 & $6.6 \times 10^{13}$ & 153 \\
\hline \multirow{2}{*}{ CDT-FBTZ } & Bar-coating & 4.9 & 0.28 & -28 & 79 & $3.1 \times 10^{13}$ & 79 \\
\hline & Spin-coating & 3 & 0.16 & -32 & 96 & $4.3 \times 10^{13}$ & 94 \\
\hline \multirow{2}{*}{ CDT-PTZ } & Bar-coating & 17 & 0.95 & -30 & 58 & $3.0 \times 10^{13}$ & 65 \\
\hline & Spin-coating & 6.2 & 0.31 & -33 & 81 & $4.0 \times 10^{13}$ & 93 \\
\hline
\end{tabular}

In an effort to clarify the effect of the microstructural ordering of the CDT-based D-A-type copolymer films on their charge-transport characteristics and electronic structures in more detail, temperature-variable measurements on the CDT Series-based PFETs at temperatures from 160 to $340 \mathrm{~K}$ were carried out. As shown in Figure S3 of the Supplementary Materials, the electrical current of the PFETs increased as the temperature increased, which indicated that charge carriers were transferred via thermally activated hopping [28-30]. In accordance with the Arrhenius equation of $\mu=\mu_{0} \exp \left(-E_{a} / k_{B} T\right)$ [31], the activation energies $\left(E_{a}\right)$ of the PFETs were extracted and found to be 89,79 , and $58 \mathrm{meV}$ for bar-coated CDT-BTZ, CDT-FBTZ, and CDT-PTZ PFETs, whereas those were 116, 96, and $81 \mathrm{meV}$ for spin-coated PFETs, as in Figure 6a-c. The activation energy indicates the required energy for hopping transfer between localized states; thus, the reduced hopping 
energies for the bar-coated CDT-based PFETs implied that the electronic states of the barcoated PFETs were more delocalized than those of the spin-coated PFETs. Moreover, in order to ensure the enhanced electronic states of the bar-coated PFETs, the density of states (DOS) of the films was extracted, using the relation as below [32-34]:

$$
g(E)=\frac{N}{\sigma \sqrt{2 \pi}} \exp \left(-\frac{E^{2}}{2 \sigma^{2}}\right)
$$

where $N$ is the total concentration of charge traps and $\sigma$ is the width of the trap distributions. Figure $6 \mathrm{~d}-\mathrm{f}$ shows the estimated density of states (DOS) of the spin- and bar-coated PFETs, respectively. It is clearly seen that the trap states of the bar-coated PFETs are more narrowly and shallowly (more delocalized) distributed than those of the spin-coated PFETs. The width of the trap distributions $(\sigma)$ were estimated to be 153,94 , and $93 \mathrm{meV}$ for the spin-coated CDT-BTZ, CDT-FBTZ, and CDT-PTZ PFETs, whereas it decreased to be 95, 79 , and $65 \mathrm{meV}$ for the bar-coated PFETs, respectively. In addition, the total concentrations of the charge traps $(N)$ were estimated to be $6.6,4.3$, and $4.0 \times 10^{13} \mathrm{~cm}^{-2}$ for the spin-coated CDT-BTZ, CDT-FBTZ, and CDT-PTZ PFETs, whereas they significantly decreased to be $4.2,3.1$, and $3.0 \times 10^{13} \mathrm{~cm}^{-2}$ for the bar-coated PFETs. As mentioned, these remarkable enhancements in the electronic structures of the bar-coated, CDT-based polymeric films were attributed to the microstructural ordering through the bar-coating-driven gradual drying [21,35]. Semiconducting polymers consist of a long molecular chain that is twisted and a tangled wire, of which disordered phases inevitably exist in the film. The disordered phases would be the source of trap sites that impede charge transport in the film. Thus, it is highly desirable to convert the disordered phases into the ordered phase for highperformance PFETs. As identified with atomic force microscopy, UV/Vis absorption spectra, and charge-transport analyses, the molecular ordering was considerably improved by the bar-coating; thus, the charge-transport characteristics of the bar-coated CDT-based PFETs were significantly enhanced.

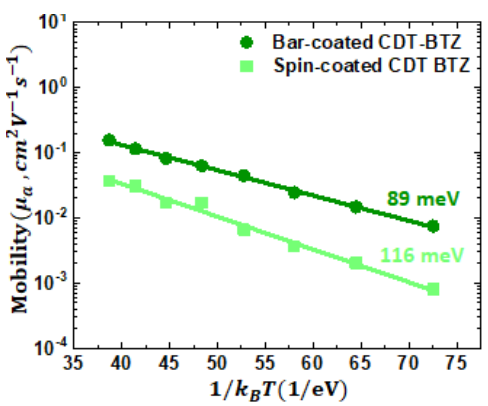

(a)

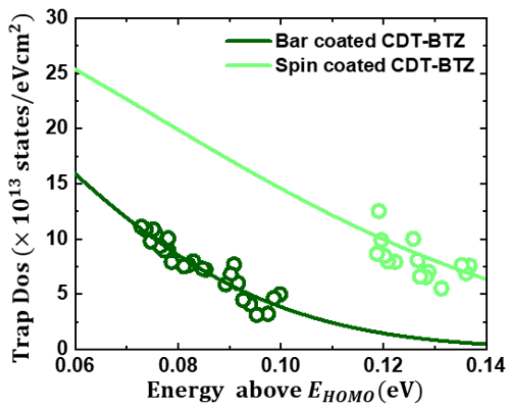

(d)

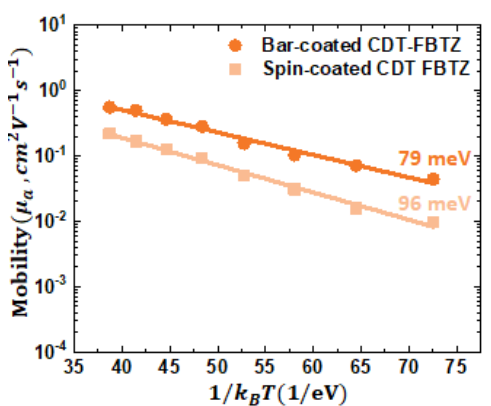

(b)

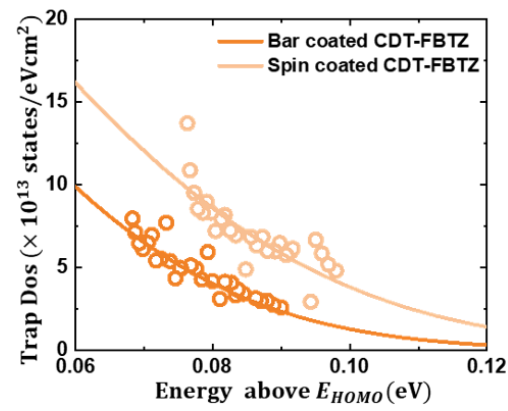

(e)

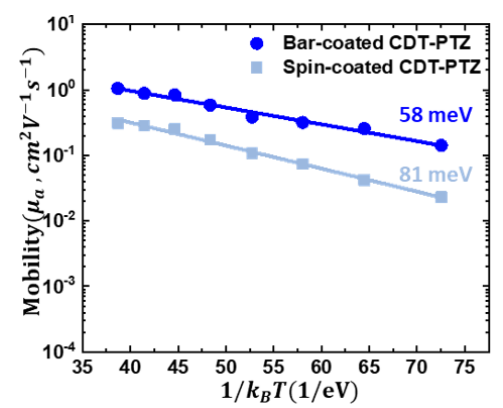

(c)

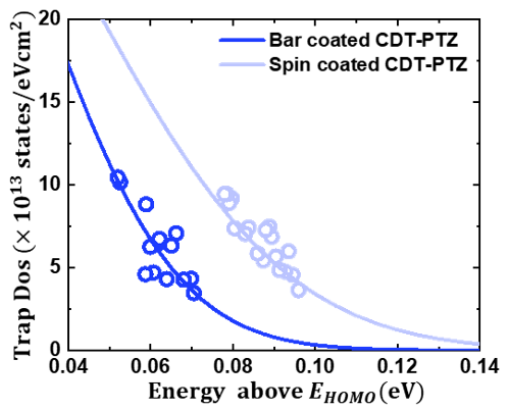

(f)

Figure 6. Linear mobility as a function of $1 / T$ for the spin- and bar-coated (a) CDT-BTZ-, (b) CDTFBTZ-, and (c) CDT-PTZ-based PFETs. Extracted charge trap density of states (DOS) of the spin- and bar-coated (d) CDT-BTZ-, (e) CDT-FBTZ-, and (f) CDT-PTZ-based PFETs above the HOMO energy level, $E_{\text {HOMO }}$. The DOS results were fitted to the Gaussian DOS model. 


\section{Conclusions}

In this study, the structural characteristics and charge-transport behaviors of the spinand bar-coated CDT-based conjugated copolymers, CDT-BTZ, CDT-FBTZ, and CDT-PTZ, were investigated. Compared to the spin-coated films, the bar-coated polymeric displayed remarkable improvements in molecular structures: Aligned macroscopic structures and nano-fibril microstructures with large grains were observed by optical and atomic microscopic analyses. In addition, the enhanced molecular ordering of the bar-coated polymeric films was identified by UV/Vis absorption spectra analyses, of which additional peaks and red shifts definitely were exhibited in their intramolecular peaks. These improved structural characteristics were regarded to be attributed to the gradual drying from the edge to the center of the bar coating, and led to the high-performance PFETs. As expected, the electrical characteristics of the bar-coated PFETs were remarkably enhanced: The hole currents $\left(I_{d s}\right.$ at $\left.V_{g s}=-60 \mathrm{~V}\right)$ increased by an order of magnitude, and the field-effect mobilities significantly increased by factors of 2 4 compared to those of the spin-coated PFETs. In more detail, the temperature-variable current-voltage analyses of the bar-coated PFETs revealed that the required hopping activation energies significantly decreased and the density of states became narrower and shallower, which obviously were attributed to the molecular ordering. Thus, we concluded that the bar-coating method offers practical benefits for improving the molecular ordering, thereby resulting in the high-performance CDT-based PFETs.

Supplementary Materials: The following are available online at https:/ / www.mdpi.com/article/ 10.3390/polym14010002/s1. Figure S1: The histogram showing the number of devices (PFETs) according to mobility, Figure S2: Comparison of transfer characteristics of PFETs at initial state and after 30 days, Figure S3: Temperature dependence of the transfer curves in the linear regime.

Author Contributions: D.K. and M.Y. have equal contribution and considered as first authors. Devices' fabrication and characterization, data curation, writing—original draft: D.K. and M.Y.; supervision, project administration, funding acquisition, writing - review \& editing: J.L. All authors have read and agreed to the published version of the manuscript.

Funding: This research is supported by the Basic Science Research Program through the National Research Foundation of Korea (NRF) funded by the Ministry of Science, ICT \& Future Planning (2021R1A2C1007212).

Data Availability Statement: The data that support the findings of this study are available from the corresponding authors upon reasonable request.

Conflicts of Interest: The authors declare no conflict of interest.

\section{References}

1. Wadsworth, A.; Chen, H.; Thorley, K.J.; Cendra, C.; Nikolka, M.; Bristow, H.; Moser, M.; Salleo, A.; Anthopoulos, T.D.; Sirringhaus, H.; et al. Modification of indacenodithiophene-based polymers and its impact on charge carrier mobility in organic thin-film transistors. J. Am. Chem. Soc. 2020, 142, 652-664. [CrossRef] [PubMed]

2. Li, X.; Huang, H.; Angunawela, I.; Zhou, J.; Du, J.; Liebman-Pelaez, A.; Zhu, C.; Zhang, Z.; Meng, L.; Xie, Z.; et al. Effects of short-axis Alkoxy substituents on molecular self-assembly and photovoltaic performance of indacenodithiophene-based acceptors. Adv. Funct. Mater. 2020, 30, 1906855. [CrossRef]

3. Zhifeng, D.; Taotao, A.; Rui, L.; Wei, Y.; Kaili, Z.; Huiling, D.; Haichang, Z. Conjugated polymers containing building blocks 1,3,4,6-Tetraarylpyrrolo[3,2-b]pyrrole-2,5-dione (isoDPP), benzodipyrrolidone (BDP) or naphthodipyrrolidone (NDP): A review. Polymers 2019, 11, 1683. [CrossRef]

4. Chen, H.; Guo, Y.; Yu, G.; Zhao, Y.; Zhang, J.; Gao, D.; Liu, H.; Liu, Y. Highly $\pi$-extended copolymers with diketopyrrolopyrrole moieties for high-performance field-effect transistors. Adv. Mater. 2012, 24, 4618-4622. [CrossRef]

5. $\quad$ Estrada, L.A.; Stalder, R.; Abboud, K.A.; Risko, C.; Brédas, J.L.; Reynolds, J.R. Understanding the electronic structure of isoindigo in conjugated systems: A combined theoretical and experimental approach. Macromolecules 2013, 46, 8832-8844. [CrossRef]

6. Deng, P.; Zhang, Q. Recent developments on isoindigo-based conjugated polymers. Polym. Chem. 2014, 5, 3298-3305. [CrossRef]

7. Szumilo, M.M.; Gann, E.H.; Mcneill, C.R.; Lemaur, V.; Oliver, Y.; Thomsen, L.; Vaynzof, Y.; Sommer, M.; Sirringhaus, H. Structure influence on charge transport in naphthalenediimide-thiophene copolymers. Chem. Mater. 2014, 26, 6796-6804. [CrossRef] 
8. Liu, F.; Wu, Y.; Wang, C.; Ma, J.; Wu, F.; Zhang, Y.; Ba, X. Synthesis and characterization of fully conjugated ladder naphthalene bisimide copolymers. Polymers 2018, 10, 790. [CrossRef]

9. Kiefer, D.; Giovannitti, A.; Sun, H.; Biskup, T.; Hofmann, A.; Koopmans, M.; Cendra, C.; Weber, S.; Anton Koster, L.J.; Olsson, E.; et al. Enhanced n-doping efficiency of a naphthalenediimide-based copolymer through polar side chains for organic thermoelectrics. ACS Energy Lett. 2018, 3, 278-285. [CrossRef] [PubMed]

10. Niedzialek, D.; Lemaur, V.; Dudenko, D.; Shu, J.; Hansen, M.R.; Andreasen, J.W.; Pisula, W.; Müllen, K.; Cornil, J.; Beljonne, D. Probing the relation between charge transport and supramolecular organization down to Ångström resolution in a benzothiadiazolecyclopentadithiophene copolymer. Adv. Mater. 2013, 25, 1939-1947. [CrossRef]

11. Um, J.G.; Habibpour, S.; Jun, Y.S.; Elkamel, A.; Yu, A. Development of $\pi-\pi$ interaction-induced functionalized graphene oxide on mechanical and anticorrosive properties of reinforced polyurethane composites. Ind. Eng. Chem. Res. 2020, 59, 3617-3628. [CrossRef]

12. Horie, M.; Majewski, L.A.; Fearn, M.J.; Yu, C.Y.; Luo, Y.; Song, A.; Saunders, B.R.; Turner, M.L. Cyclopentadithiophene based polymers-A comparison of optical, electrochemical and organic field-effect transistor characteristics. J. Mater. Chem. 2010, 20, 4347-4355. [CrossRef]

13. Zhang, J.; Xu, W.; Sheng, P.; Zhao, G.; Zhu, D. Organic donor-acceptor complexes as novel organic semiconductors. Acc. Chem. Res. 2017, 50, 1654-1662. [CrossRef]

14. Gupta, V.K.; Singh, R.A. An investigation on single crystal growth, structural, thermal and optical properties of a series of organic D- $\pi$-a push-pull materials. RSC Adv. 2015, 5, 38591-38600. [CrossRef]

15. Zheng, W.; Liu, J.; Guo, Y.; Han, G.; Yi, Y. Regulation of molecular orientations of A-D-A nonfullerene acceptors for organic photovoltaics: The role of end-group $\pi-\pi$ stacking. Adv. Funct. Mater. 2021, 2108551. [CrossRef]

16. Zhang, J.; Yang, L.; Zhang, M.; Wang, P. Theoretical investigation of the donor group related electronic structure properties in push-pull organic sensitizers. RSC Adv. 2013, 3, 6030-6035. [CrossRef]

17. Liu, Z.; Zhang, G.; Zhang, D. Modification of side chains of conjugated molecules and polymers for charge mobility enhancement and sensing functionality. Acc. Chem. Res. 2018, 51, 1422-1432. [CrossRef] [PubMed]

18. Chen, M.S.; Niskala, J.R.; Unruh, D.A.; Chu, C.K.; Lee, O.P.; Fréchet, J.M.J. Control of polymer-packing orientation in thin films through synthetic tailoring of backbone coplanarity. Chem. Mater. 2013, 25, 4088-4096. [CrossRef]

19. Mukherjee, T.; Sinha, S.; Mukherjee, M. Electronic structure of twisted and planar rubrene molecules: A density functional study. Phys. Chem. Chem. Phys. 2018, 20, 18623-18629. [CrossRef] [PubMed]

20. Khim, D.; Han, H.; Baeg, K.J.; Kim, J.; Kwak, S.W.; Kim, D.Y.; Noh, Y.Y. Simple bar-coating process for large-area, high-performance organic field-effect transistors and ambipolar complementary integrated circuits. Adv. Mater. 2013, 25, 4302-4308. [CrossRef] [PubMed]

21. Lee, S.B.; Kang, B.; Kim, D.; Park, C.; Kim, S.; Lee, M.; Lee, W.B.; Cho, K. Motion-programmed bar-coating method with controlled gap for high-speed scalable preparation of highly crystalline organic semiconductor thin films. ACS Appl. Mater. Interfaces 2019, 11, 47153-47161. [CrossRef]

22. Pang, B.; Tang, Z.; Li, Y.; Meng, H.; Xiang, Y.; Li, Y.; Huang, J. Synthesis of conjugated polymers containing B N bonds with strong electron affinity and extended absorption. Polymers 2019, 11, 1630. [CrossRef] [PubMed]

23. Zhang, Z.; Peng, B.; Ji, X.; Pei, K.; Chan, P.K.L. Marangoni-effect-assisted bar-coating method for high-quality organic crystals with compressive and tensile strains. Adv. Funct. Mater. 2017, 27, 1703443. [CrossRef]

24. Kanimozhi, C.; Naik, M.; Yaacobi-Gross, N.; Burnett, E.K.; Briseno, A.L.; Anthopoulos, T.D.; Patil, S. Controlling conformations of diketopyrrolopyrrole-based conjugated polymers: Role of torsional angle. J. Phys. Chem. C 2014, 118, 11536-11544. [CrossRef]

25. Kim, N.K.; Jang, S.Y.; Pace, G.; Caironi, M.; Park, W.T.; Khim, D.; Kim, J.; Kim, D.Y.; Noh, Y.Y. High-performance organic field-effect transistors with directionally aligned conjugated polymer film deposited from pre-aggregated solution. Chem. Mater. 2015, 27, 8345-8353. [CrossRef]

26. Bencheikh, F.; Duché, D.; Ruiz, C.M.; Simon, J.J.; Escoubas, L. Study of optical properties and molecular aggregation of conjugated low band gap copolymers: PTB7 and PTB7-Th. J. Phys. Chem. C 2015, 119, 24643-24648. [CrossRef]

27. Kamatham, N.; Ibraikulov, O.A.; Durand, P.; Wang, J.; Boyron, O.; Heinrich, B.; Heiser, T.; Lévêque, P.; Leclerc, N.; Méry, S. On the impact of linear siloxanated side chains on the molecular self-assembling and charge transport properties of conjugated polymers. Adv. Funct. Mater. 2021, 31, 2007734. [CrossRef]

28. Schwarze, M.; Gaul, C.; Scholz, R.; Bussolotti, F.; Hofacker, A.; Schellhammer, K.S.; Nell, B.; Naab, B.D.; Bao, Z.; Spoltore, D.; et al Molecular parameters responsible for thermally activated transport in doped organic semiconductors. Nat. Mater. 2019, 18, 242-248. [CrossRef] [PubMed]

29. Fratini, S.; Ciuchi, S. Bandlike motion and mobility saturation in organic molecular semiconductors. Phys. Rev. Lett. 2009, 103, 266601. [CrossRef]

30. Lee, J. Physical modeling of charge transport in conjugated polymer field-effect transistors. J. Phys. D Appl. Phys. 2021, 54, 3255. [CrossRef]

31. Laidler, K.J. The development of the arrhenius equation. J. Chem. Educ. 1984, 61, 494-498. [CrossRef]

32. Kalb, W.L.; Batlogg, B. Calculating the trap density of states in organic field-effect transistors from experiment: A comparison of different methods. Phys. Rev. B 2010, 81, 035327. [CrossRef] 
33. Lang, D.V.; Chi, X.; Siegrist, T.; Sergent, A.M.; Ramirez, A.P. Amorphouslike density of gap states in single-crystal pentacene. Phys. Rev. Lett. 2004, 93, 8-11. [CrossRef] [PubMed]

34. Sirringhaus, H. Device physics of solution-processed organic field-effect transistors. Adv. Mater. 2005, 17, 2411-2425. [CrossRef]

35. Park, K.S.; Kwok, J.J.; Dilmurat, R.; Qu, G.; Kafle, P.; Luo, X.; Jung, S.H.; Olivier, Y.; Lee, J.K.; Mei, J.; et al. Tuning conformation, assembly, and charge transport properties of conjugated polymers by printing flow. Sci. Adv. 2019, 5, eaaw7757. [CrossRef] [PubMed] 